\title{
Analysis of the exhaust emissions from hybrid vehicle during RDE test
}

\author{
Andrzej Ziolkowski ${ }^{1}$, Pawel Daszkiewicz ${ }^{1}$,Lukasz Rymaniak $^{1}$, Paweł Fuc ${ }^{1}$, and Pawel Ukleja ${ }^{2}$ \\ ${ }^{1}$ Poznan University of Technology, Faculty of Transport Engineering, 60-965 Poznan, ul. Piotrowo 3, Poland \\ ${ }^{2}$ Lexus Poznan, 61-961 Poznan, ul. Lechicka 7, Poland
}

\begin{abstract}
The introduction of the Euro 6c emission norm in 2017 resulted in a change of the type approval procedures. The most important of these was the replacement of the NEDC test with WLTC test with different procedures. In addition, the research was extended to include emission tests in real operating conditions (RDE). Such tests are enforced for heavy vehicles since 2014. PEMS apparatus was used for the measurements, which has been used by many research and development centers to carry out exhaust emissions measurements long before the applicable procedures were introduced. The article presents the methodology of conducting RDE measurements in accordance with the requirements defined by the Euro $6 \mathrm{c}$ norm. The focus in this case was primarily on the selection of the test route in the Poznan agglomeration. After determining its course, RDE measurements were made for a vehicle with a hybrid drive. The test route parameters have complied with the applicable requirements. All requirements were met and it was possible to analyze the exhaust emissions. The main focus being the determination of exhaust emissions from the entire test and in accordance with the EMROAD method. The CF (Comformity Factor) coefficients were also determined for both methods and compared with the applicable legal values. An analysis of the hybrid drive system operation was carried out, defining the degree of hybridization, which is the portion of the vehicle travel using only the electric motor of the drive system throughout the whole test. All analyzes were carried out in individual sections of the test: urban, rural and motorway.
\end{abstract}

\section{Introduction}

Increasing the efficiency and reducing the fuel consumption of drive systems is a complex multifaceted process that every car vehicle manufacturer performs according to an independently developed and adopted strategy [1-5]. This often requires major structural changes to be made both to the engine itself and to its accessories. Due to the cyclical changes in regulations regarding exhaust emissions, manufacturers are obliged to adapt their products to the limits as given. These regulations are the main factor determining the development of engines and propulsion systems. In terms of efficiency, the average individual $\mathrm{CO}_{2}$ emissions are of key importance. It is the reduction in the consumption of conventional energy sources (primarily gasoline and diesel) by the road transport sector that is currently one of the main challenges awaiting manufacturers of motor vehicles. The implementation of the Euro $6 \mathrm{c}$ emissions norm for PC and LDV category vehicles and the introduction of the Euro VI standard for HDV (Heavy Duty Vehicle) vehicles required the use of an extensive exhaust aftertreatment system consisting of a series of catalytic converters and a diesel particulate filter. Each of these elements generates power losses resulting from the internal resistance of the exhaust gas flow, thereby increasing the share of energy losses in the exhaust system, which also increases the fuel consumption of the engine [6-10].

In the long-term, the constructors assume that it will be possible to replace the classic internal combustion engine with a fuel cell powered by hydrogen, which will become the main source of energy. It is also one of the main directions of drive systems development. Its large scale implementation now faces a number of difficulties for passenger cars, however, and there are only a few single vehicle models that are powered by hydrogen on the market. The hydrogen refueling infrastructure is also not developed. Electric vehicles using classic energy storage systems are now more popular. In their case, the most troublesome aspect is the time needed for recharging, which can last up to several hours. For this reason, among the driving alternatives, vehicles with hybrid propulsion systems are most often selected, characterized by cooperation of at least two energy sources, at least one of which must be a secondary source. The term "primary source of energy" should be understood as a source with a possibly constant expenditure, supplying energy to the system independently of the changes taking place in this system. It can be a thermal engine, a thermal motor coupled with 
a power generator or an electrical network. The original source of energy is characterized by irreversible work. The term "secondary energy source" (energy accumulator) is understood as a device that accumulates part of the primary energy as well as the kinetic energy of the vehicle when braking and supplies the power gathered at moments of peak external loads. It can be an electrochemical, hydraulic or mechanical battery. In work [11] was performed a preliminary study of the physicochemical properties of hybrid organic-inorganic gel electrolytes for $\mathrm{Li}$-ion batteries. The secondary energy source is characterized by reversible operation. A hybrid vehicle is one in which propulsion energy can, in given operating conditions, be provided from two or more kinds or types of sources, or converters of energy, of which at least one source or transducer must be present in the vehicle [12]. The article presents the results of exhaust emission tests from a vehicle using hybrid drive performed in accordance with the RDE procedures, which are currently one of the main directions of development of emission testing procedures.

\section{Test route selection in accordance with the RDE test requirements}

In September 2017 the Euro 6c standard was introduced for the group of PC and LDV vehicles, which in addition to the change of exhaust emission limits introduced significant changes in how the exhaust measurement procedures should be performed. The applicable NEDC approval test was replaced by WLTC procedures and the obligation to perform emission RDE measurements under real operation conditions was introduced. This requires the use of equipment from the PEMS group. In order to ensure comparable measurement conditions, requirements for the test route, which will be used for testing, were also specified. The most important requirements include [13-14]:

a) the test route should consist of three sections:

- urban section, length min. $16 \mathrm{~km}$, maximum vehicle speed of $60 \mathrm{~km} / \mathrm{h}$, lasting between $29-44 \%$ of the total test time with a tolerance of $10 \%$,

- rural section, maximum vehicle speed between 60-90 $\mathrm{km} / \mathrm{h}$, length $\min .16 \mathrm{~km}$, lasting between $23-43 \%$ of the total test time with a tolerance of $10 \%$,

- motorway section, vehicle speed over $90 \mathrm{~km} / \mathrm{h}$, length min. $16 \mathrm{~km}$, lasting between $23-43 \%$ of the total test time with a tolerance of $10 \%$,

b) the share of the time spent idle by the vehicle in the urban section should be in the range of $6-30 \%$,

c) in the motorway section, the vehicle is expected to travel at a speed of at least $100 \mathrm{~km} / \mathrm{h}$ for a minimum of 5 minutes,

d) the maximum speed of the vehicle should not exceed $145 \mathrm{~km} / \mathrm{h}$ (it is permitted to travel at a higher speed, but its share must not exceed 3\%),

e) the whole test should last between 90-120 minutes,

f) the test should start with the urban section, then it should move on to the rural and motorway sections (minor deviations from this order are acceptable), g) the relative difference in the elevation between the starting and ending points of the test should not exceed $100 \mathrm{~m}$,

h) the vehicle should be driven by a single driver in all sections,

i) pauses or stops in the measurements are not acceptable.

The test route selection in accordance with the presented guidelines requires experience in carrying out exhaust emissions measurements in real operating conditions. The authors of the publication have many years of experience performing these types of measurements and thanks to this a research route, which meets the requirements of the norm, has been developed along the routes of the Poznan agglomeration. It begins at the Poznan University of Technology and continues through the neighboring districts of the city (southeastern part) and through its center (urban section). After driving through the city center, it leads towards the eastern city limits, then follows the main arterial roads towards the national road No. 92 (Fig. 1).

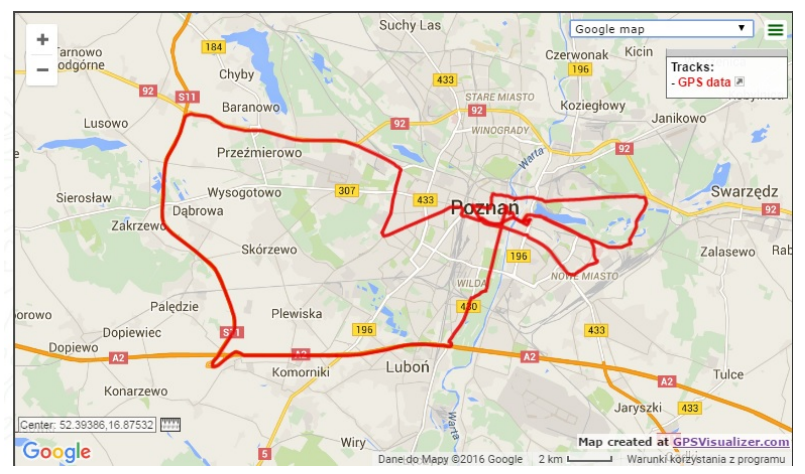

Fig. 1. Poznań-RDE road [15].

During this journey, there is a smooth transition from the urban to the rural section, which ends on the S11 expressway constituting the western city bypass route. The last stage of the test, which is the motorway section, begins there. This phase runs mainly through the southern bypass of the city, which is the A2 motorway. The motorway section ends after leaving the PoznańKrzesiny junction. The last stage of the route is returning to the location where the test began. The total length of the developed research route is in the range of $75-80 \mathrm{~km}$. Such a discrepancy in the length of the route is related to the required travel time, which should be at least 90 and a maximum of 120 minutes. Depending on the traffic, it is acceptable to finish the measurements before returning to the starting location, so as not to exceed the maximum RDE test duration.

\section{Test vehicle characteristics}

In RDE tests, a vehicle with a hybrid drive system with mixed configuration was used (Fig. 2). It is composed of a piston combustion engine constituting the primary source of energy and of the set of an electric motor with a Nickel-metal hydride battery acting as the secondary source of energy (tab 1.). 


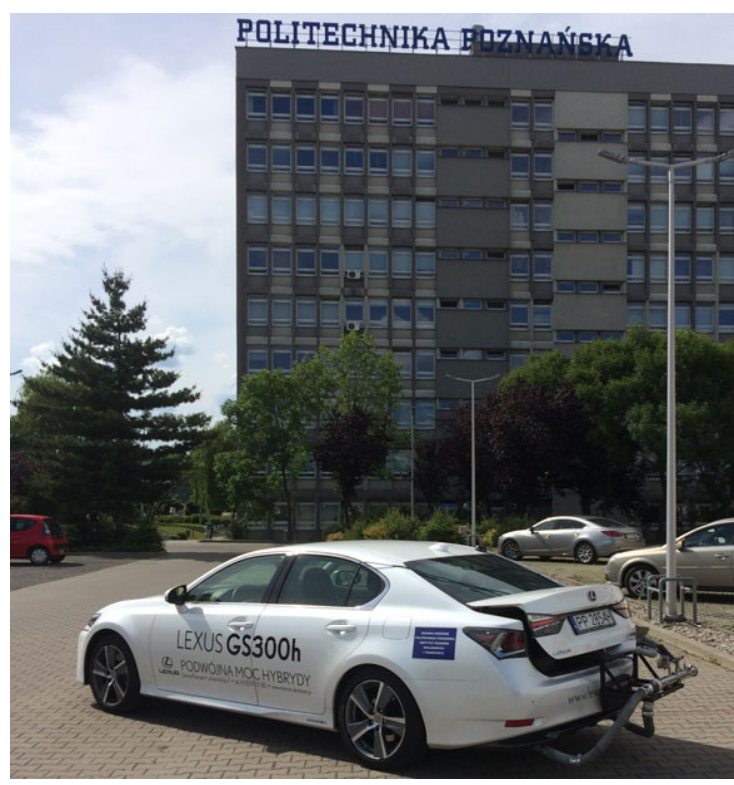

Fig. 2. View of tested vehicle.

Table 1. Characteristics of the hybrid vehicle used for the test.

\begin{tabular}{|c|c|}
\hline Parameter & Value \\
\hline \multicolumn{2}{|c|}{ Engine } \\
\hline Type of engine & Spark ignition \\
\hline Displacement & $2.494 \mathrm{dm}^{3}$ \\
\hline Number of cylinders & 4 \\
\hline Power output & $133 \mathrm{~kW} @ 6000 \mathrm{rpm}$ \\
\hline Torque & $221 \mathrm{Nm} @ 4200-5400$ rpm \\
\hline Emissions standard & Euro $6 \mathrm{c}$ \\
\hline Exhaust gas aftertreatment & TWC with lambda control \\
\hline \multicolumn{2}{|c|}{ Electric motor/generator } \\
\hline Type of motor & $\begin{array}{c}\text { Permanent magnet, } \\
\text { synchronous }\end{array}$ \\
\hline Max. voltage & $650 \mathrm{~V}$ \\
\hline Power output & $105 \mathrm{~kW}$ \\
\hline Torque & $300 \mathrm{Nm}$ \\
\hline \multicolumn{2}{|c|}{ Hybrid battery } \\
\hline Battery type & Nickel-metal hydride \\
\hline Nominal voltage & $230.4 \mathrm{~V}$ \\
\hline Number of cells & 192 \\
\hline \multicolumn{2}{|c|}{ Hybrid drive system } \\
\hline System type & Series/parallel full hybrid \\
\hline Max. power & $164 \mathrm{~kW}$ \\
\hline
\end{tabular}

The four-cylinder internal combustion engine has a displacement of $2.494 \mathrm{dm}^{3}$. It is equipped with a VVT-i timing DOHC type system with four valves per cylinder. The engine generates a maximum power of $133 \mathrm{~kW}$ at $6000 \mathrm{rpm}$ and a maximum torque of $221 \mathrm{Nm}$ in the range of 4200-5400 rpm. It also uses a direct gasoline injection system. The power of the electric motor is $105 \mathrm{~kW}$ and its maximum torque is $300 \mathrm{Nm}$. The motor produces a voltage not exceeding $650 \mathrm{~V}$. The maximum power of the drive system of the tested vehicle is equal to $164 \mathrm{~kW}$.

\section{Equipment used for tests}

The first instrument used for research was the Semtech-Ecostar. This is another device from the Setmtech ${ }^{\circledR}$ series - a successor to the Semtech Ds analyzer. The main difference between these devices is that Semtech-Ecostar is made up of separate modules (Fig. 3):

- FEM module for measuring the concentration of $\mathrm{CO}_{2}, \mathrm{CO}, \mathrm{HC}$ (NDIR analyzer),

- $\mathrm{NO}_{\mathrm{x}}$ module for the measurement of $\mathrm{NO}_{\mathrm{x}}(\mathrm{NO}$ and $\mathrm{NO}_{2}$ ) concentration using the NDUV analyzer,

- FID module to measure THC with a FID analyzer,

- PDM module to power supply system for each component.

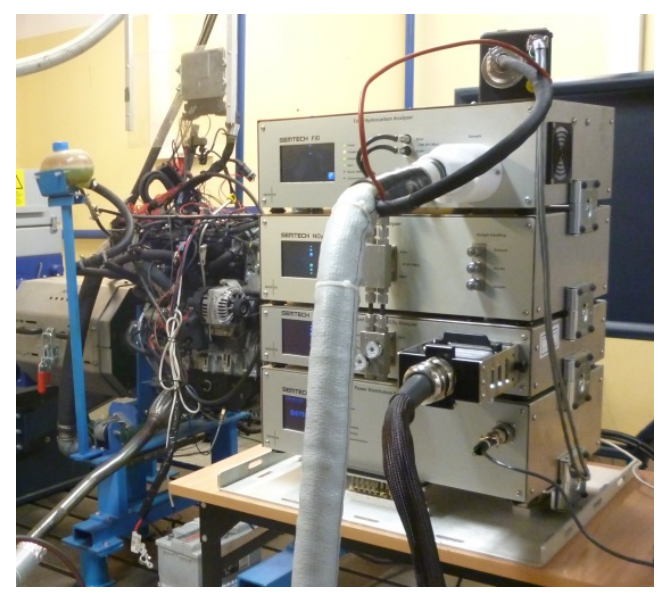

Fig. 3. Semtech-Ecostar instrument used to measure emissions in accordance with the RDE methodology.

In the case when of all the modules are used (of the gas measurement section) they must be connected together by a CAN communication wire (green lines in Fig. 4). The FEM module is connected via a special cable with a flow meter for measuring thermodynamic parameters of exhaust gases (mass flow, temperature and pressure). This line is supplied a sample of exhaust gas that passed through the NDIR analyzer (measuring $\mathrm{CO}_{2}$, $\mathrm{CO}$ and $\mathrm{HC}$ ) is directed to the $\mathrm{NO}_{\mathrm{x}}$ module with three connectors, wherein the measurement of $\mathrm{NO}$ and $\mathrm{NO}_{2}$ takes place.

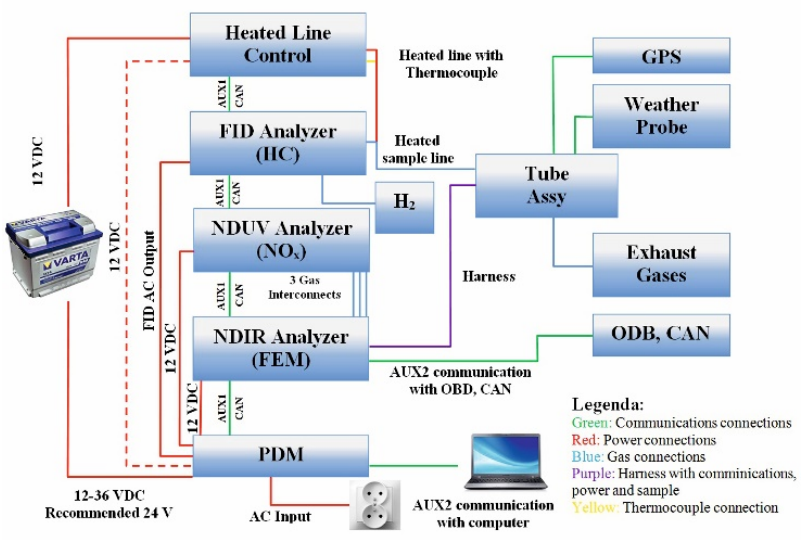

Fig. 4. Diagram of the Semtech-Ecostar system used for testing - section responsible for the measurement of gaseous compounds.

Apart from the exhaust gas sample a special conduit transmits the signal from the vehicle global positioning system (GPS) and weather sensor used to measure the 
atmospheric conditions (temperature, pressure, humidity), which are connected to the flow meter. A computer for system control and a signal converter from the vehicle's diagnostic system are connected using the AUX2 connector to the PDM, FEM and $\mathrm{NO}_{\mathrm{x}}$ modules. Each module is equipped with one AUX1 and one AUX2 connection point. The signal from the power supply module for the heated wire is sent to the FID module. Semtech-Ecostar device can be powered by a PDM module, to which voltage is supplied from the grid or from the car battery. It is also possible to directly connect the modules to the mains. Due to the modular design of the instrument it can perform measurement of all gaseous compounds simultaneously, or separately using a single module.

\section{Test results and analysis}

Before analyzing the RDE test results, it is necessary to check whether the drive cycle met the requirements outlined in the norms. As described previously in the article the authors have selected a test route in the Poznań agglomeration dedicated to RDE research. Measurements for a hybrid vehicle were carried out on this route. The drive took place on a working day of the week in the afternoon hours at normal traffic levels. The test duration was 91 minutes and during this time the vehicle covered a distance of $70.3 \mathrm{~km}$. The criterion regarding the duration of the journey has been met. The requirement for a minimum distance of $16 \mathrm{~km}$ for individual test sections (urban, rural, motorway) together with each section's overall share in the RDE test were also met. Other requirements that must be met are presented in Tab. 2. It was found that the measurements carried out met the requirements set out in the standard and further analysis of the obtained parameters is therefore possible.

Table 2. Characteristic of RDE road

\begin{tabular}{|l|c|c|c|}
\hline No & Parameter & Unit [requerement] & Value \\
\hline 1. & Total trip distance & $\mathrm{km} \mathrm{[-]}$ & 70.3 \\
\hline 2. & Total trip duration & $\mathrm{min} .[90-120]$ & 91.0 \\
\hline 3. & Cold start duration & $\mathrm{min} .[5]$ & 5.0 \\
\hline 4. & Urban distance & $\mathrm{km} \mathrm{[>16]}$ & 29.7 \\
\hline 5. & Rural distance & $\mathrm{km} \mathrm{[>16]}$ & 17.7 \\
\hline 6. & Motorway distance & $\mathrm{km} \mathrm{[>16]}$ & 22.9 \\
\hline 7. & Urban distance share & $\%[29-44]$ & 42.5 \\
\hline 8. & Rural distance share & $\%[23-43]$ & 24.9 \\
\hline 9. & $\begin{array}{c}\text { Motorway distance } \\
\text { share }\end{array}$ & $\%[23-43]$ & 32.6 \\
\hline 10. & Urban average speed & $\mathrm{km} / \mathrm{h}[15-40]$ & 27.2 \\
\hline 11. & $\begin{array}{c}\text { Motorway speed } \\
\text { above } 145 \mathrm{~km} / \mathrm{h}\end{array}$ & $\begin{array}{c}\mathrm{km} / \mathrm{h} \\
{[<3 \% \mathrm{mot} . \mathrm{time}]}\end{array}$ & 2.16 \\
\hline 12. & $\begin{array}{c}\text { Motorway speed } \\
\text { above } 100 \mathrm{~km} / \mathrm{h}\end{array}$ & $\mathrm{Min} .[>5]$ & 9.28 \\
\hline 13. & Urban stop time & $5 \%[6-30]$ & 21.9 \\
\hline 14. & $\begin{array}{c}\text { Start and end points } \\
\text { elevation absolute } \\
\text { difference }\end{array}$ & $\mathrm{M}[<100 \mathrm{~m}]$ & 14.1 \\
\hline 15. & $\begin{array}{c}\text { Cumulative positive } \\
\text { elevation gain }\end{array}$ & $\begin{array}{c}\mathrm{m} / 100 \mathrm{~km} \\
{[<1200 \mathrm{~m} / 100} \\
\mathrm{km}]\end{array}$ & 301.1 \\
\hline
\end{tabular}

The first test phase covered the urban section where the vehicle speed should not exceed $60 \mathrm{~km} / \mathrm{h}$. For the most part of this section, this rule was followed, however, there were single areas where the vehicle speed exceeded that limit and the test shifted into the rural section. The exhaust emission norms permit this to happen. The length of the urban section was $29.7 \mathrm{~km}$, and the average speed was $27.2 \mathrm{~km} / \mathrm{h}$. In the rural section, which was the next phase of the RDE test, areas occurred where the vehicle only achieved speeds that qualified for the urban phase.

This resulted from the road congestion present during testing, where the traffic prevented a smooth drive through this section. The length of this section of the test was $17.7 \mathrm{~km}$. In the case of motorway driving the vehicle reached a maximum speed of $156 \mathrm{~km} / \mathrm{h}$, but most of the time the speed did not exceeded $145 \mathrm{~km} / \mathrm{h}$. Therefore, the conditions stating that $3 \%$ of the time of the drive section with the speed exceeding $145 \mathrm{~km} / \mathrm{h}$ and minimum 5 minutes travelling the speed above $100 \mathrm{~km} / \mathrm{h}$ were both fulfilled. The smallest change in vehicle acceleration was observed for the motorway section (Fig. 5).

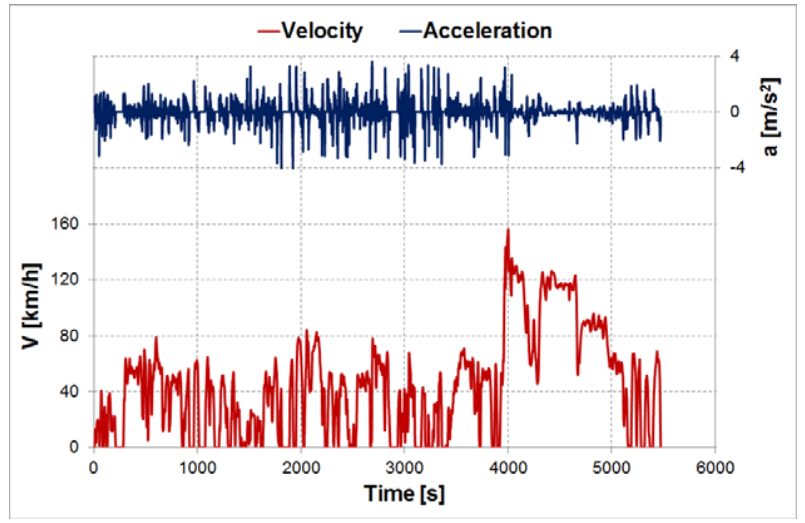

Fig. 5. The speed and acceleration of the vehicle during the RDE test.

In the case of vehicles with hybrid drives, it is also reasonable to analyze the share of drive time spent using only electric power for propulsion in the RDE test - this share was defined as hybridization or the degree of hybridization. To determine the degree of hybridization in the test drive, it was necessary to analyze the data recorded from the OBD system, and in particular the engine crankshaft speed. A basic 0-1 system was used, in which 0 means the use of the internal combustion engine and 1 means only the electric drive system is used. This article does not take into account the parallel operation mode of the drive system, where energy from the combustion engine and the electrical motor is used in combination. During the RDE test, the degree of hybridization was measured at $46 \%$. This means that almost half of the travel time to the test drive was spent using only the electric motor for propulsion. This was evident especially in the urban and rural test sections (Fig. 6). 


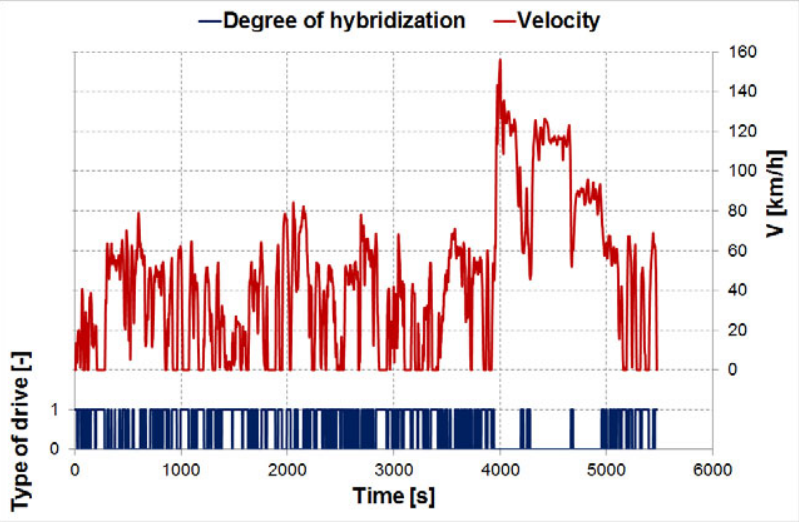

Fig. 6. Determination of the degree of hybridization during the RDE test.

In addition to determining the degree of hybridization for the entire RDE drive cycle, the operating conditions of the internal combustion engine for the individual test sections were also analyzed. The characteristics of the share of operating time in crankshaft speed and engine load intervals were used to represent the results. In the urban section, the share of the electrical power was observed to be dominant, because $58 \%$ of the whole operating time the internal combustion engine was not utilized at all (Fig. 7).

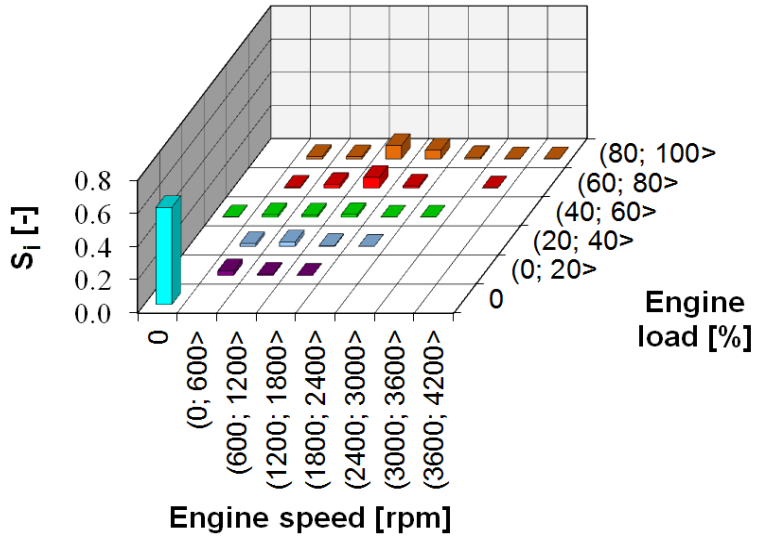

Fig. 7. Operating time density characteristics in the crankshaft rotational speed and engine load ranges for urban driving conditions in RDE test

In the remainder of this phase, it was registered that the engine was operating in the engine speed range 0 $4800 \mathrm{rpm}$. In this range the largest share was for the engine load from two ranges $(60 ; 80 \%>$ and $(80 ; 100 \%>$. They represented a total of $27 \%$ of total operating time.

In the rural section of the RDE test, the degree of hybridization of the propulsion system was much lower than in the urban section. It amounted to $22 \%$ (Fig. 8). However, the distribution of the operating points of the internal combustion engine was similar. The range of rotational speed of the crankshaft was increased to 5400 $\mathrm{rpm}$. Driving with the highest load accounted for $52 \%$ of total engine operating time. The range of small and medium loads $(0 ; 60 \%>$ was $23 \%$.

The motorway phase was characterized by the throughout operation of the internal combustion engine (Fig. 9). No work point was registered in which only the electrical drive was used. The dominant feature here was the operation of an internal combustion engine with a maximum load in the range of $(80,100 \%>$, which accounted for $80 \%$ of total operating time.

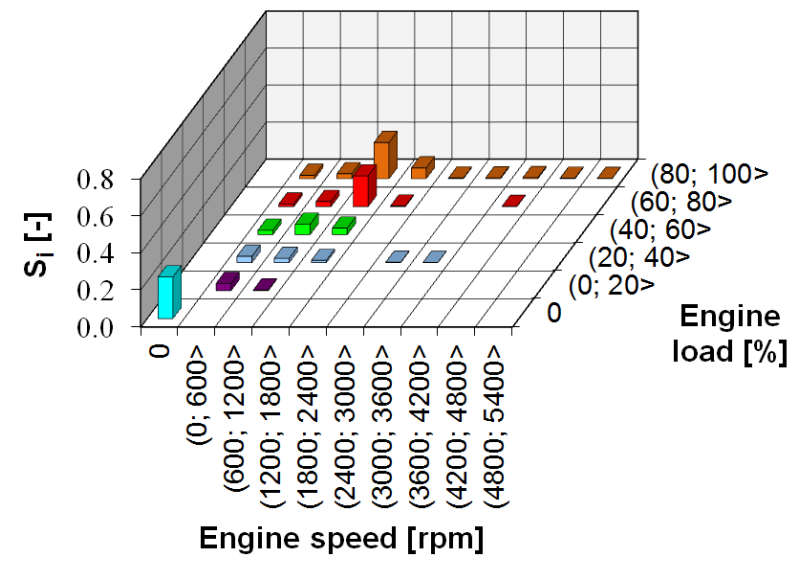

Fig. 8. Operating time density characteristics in the crankshaft rotational speed and engine load ranges for rural driving conditions in RDE test.

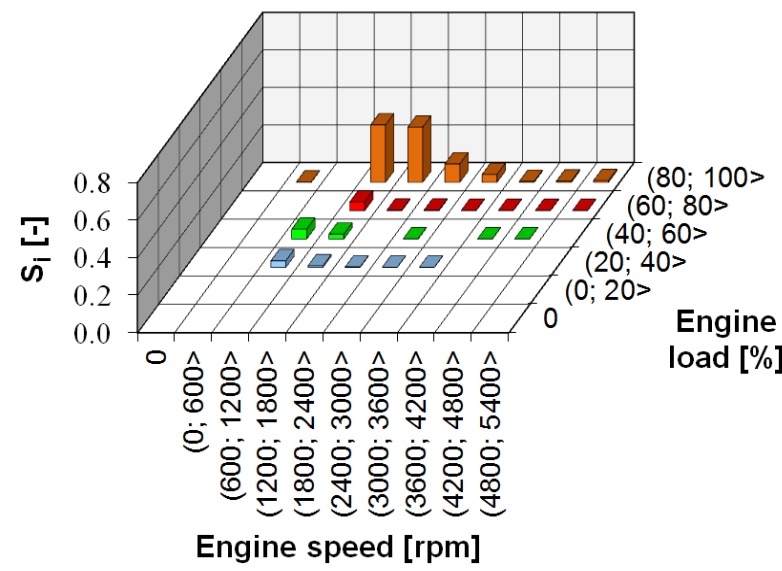

Fig. 9. Operating time density characteristics in the crankshaft rotational speed and engine load ranges for motorway driving conditions in RDE test.

This is a characteristic phenomenon for hybrid drive systems, because the motorway section travel has the highest energy demand, which can be covered exclusively by the combustion engine. There is also no recuperation of the braking energy, so in the motorway phase, the batteries are technically not replenished at all with electricity.

The next step in the analysis of the obtained test results is to determine the exhaust emissions, in particular road emissions of $\mathrm{CO}, \mathrm{NO}_{\mathrm{x}}, \mathrm{THC}$ and $\mathrm{CO}_{2}$. In this case, it was decided that the total exhaust emissions from the RDE route will be determined according to the MAW method (moving average windows), in the literature also referred to as the EMROAD method, which determines the measurement windows (on the basis of carbon dioxide emissions from the WLTC test) and on its basis determines the road emission in the RDE test. Only the $\mathrm{CO}$ and $\mathrm{NO}_{\mathrm{x}}$ road emissions were determined using this method.

In the urban RDE test phase, the road emission was $0.37 \mathrm{~g} / \mathrm{km}$ and was the smallest among the three drive 
cycle sections (Fig. 10). In the case of $\mathrm{NO}_{\mathrm{x}}$ and $\mathrm{THC}$, the highest values were achieved in the urban and motorway sections. It is worth noting that in the urban section the maximum value of $\mathrm{NO}_{\mathrm{x}}$ road emissions was obtained, which could have been the result of the low conversion rate of the TWC catalytic converter, whose efficiency is closely related to the temperature of the exhaust gases. As mentioned earlier in the urban section, the degree of hybridization of the propulsion system was calculated to be almost $60 \%$, which influenced the low temperature of the catalytic carrier in this test phase. Hence the dominant share of urban $\mathrm{NO}_{\mathrm{x}}$ emissions in the RDE test. Such a situation would not occur for a vehicle with a conventional drive system, powered with an SI engine. In the case of performing measurements in the RDE test for such a vehicle type, the largest $\mathrm{NO}_{\mathrm{x}}$ road emissions are expected to occur in the rural and motorway sections, as confirmed by other research results performed by the authors.

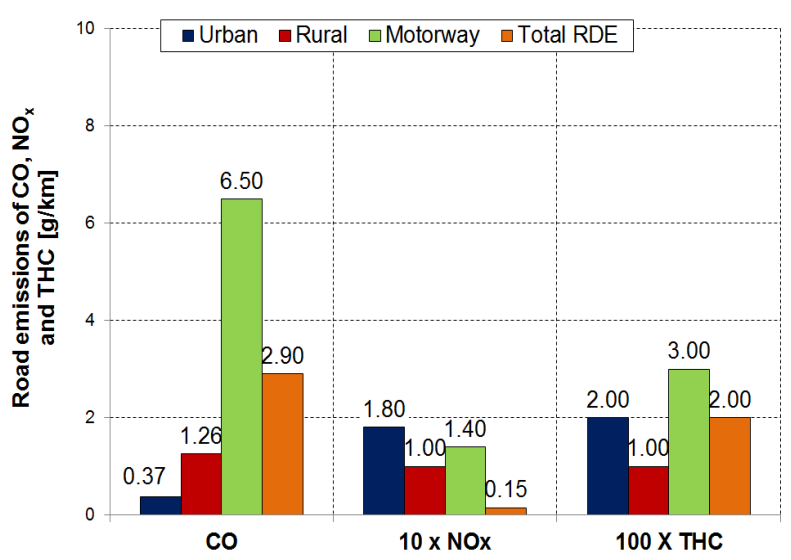

Fig. 10. Road emissions of $\mathrm{CO}, \mathrm{NO}_{\mathrm{x}}$, and $\mathrm{THC}$ in RDE test.

In order to compare the road emission obtained in the RDE test to the values listed in the Euro 6c norm, it was decided that the CF coefficient, constituting the ratio of the total emission from the RDE test to the limit values specified in the norm, needs to be determined. The CF coefficient for $\mathrm{CO}$ was 2.9, for $\mathrm{NO}_{\mathrm{x}} 2.5$ and for THC 0.23 (Fig. 11). Therefore, since according to the norm that the $\mathrm{CF}$ coefficient for $\mathrm{CO}, \mathrm{NO}_{\mathrm{x}}$ should not exceed 2.1, this condition was not met in any of the compounds considered.

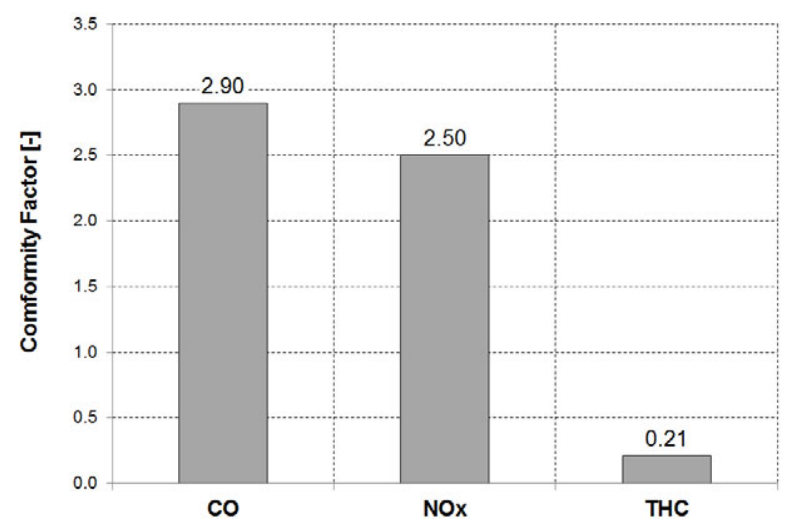

Fig. 11. Comformity factor $(\mathrm{CF})$ of $\mathrm{CO}, \mathrm{NO}_{\mathrm{x}}$, and $\mathrm{THC}$ determined during RDE tests (all results).
When determining the $\mathrm{CF}$ coefficient according to the EMROAD method for $\mathrm{CO}$ and $\mathrm{NO}_{\mathrm{x}}$ road emissions, similar values were obtained as from the calculations made for the entire RDE test. Both compounds also did not meet the 2.1 limit value (Fig. 12).

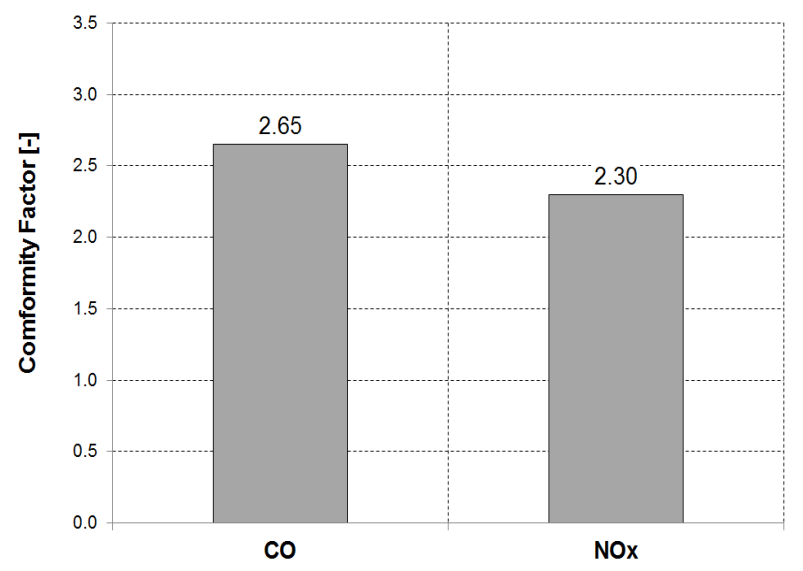

Fig. 12. Comformity factor $(\mathrm{CF})$ of $\mathrm{CO}, \mathrm{NO}_{\mathrm{x}}$, determined during RDE tests (EMROAD procedure).

The last stage of the analysis of the obtained test results in the RDE test was the evaluation of the vehicle fuel consumption. The carbon balance method was used to achieve this, in which the road emissions of $\mathrm{CO}$, THC and $\mathrm{CO}_{2}$ are used to assess the fuel use. The values of the first two compounds were presented earlier, while the $\mathrm{CO}_{2}$ road emissions were as follows:

a) urban section $-174.6 \mathrm{~g} / \mathrm{km}$,

b) rural section $-114.7 \mathrm{~g} / \mathrm{km}$

c) motorway section $-180.9 \mathrm{~g} / \mathrm{km}$.

d) total $-161 \mathrm{~g} / \mathrm{km}$.

The mean fuel consumption value for the whole RDE test was $6.42 \mathrm{dm}^{3} / 100 \mathrm{~km}$ (Fig. 13). The smallest value was recorded in the rural phase, while the largest in the motorway phase.

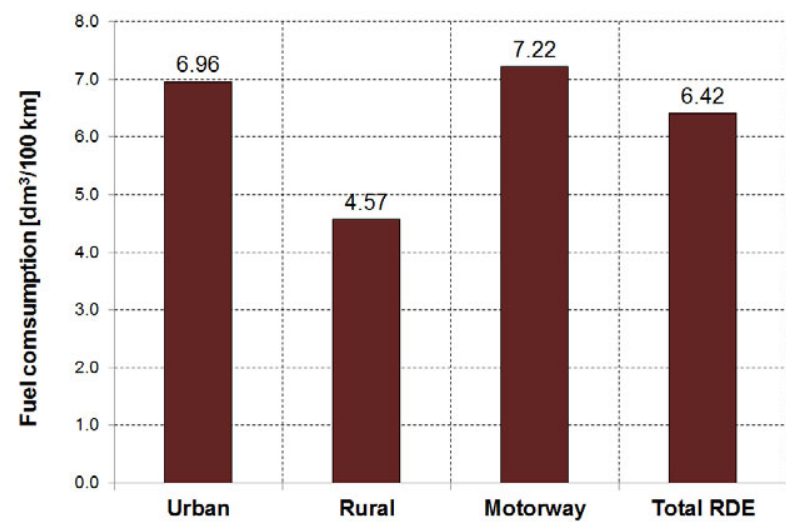

Fig. 13.Fuel consumption determined during RDE tests (all results)

\section{Conclusion}

The measurements carried out in the article confirmed the correct selection of the research route in the Poznan agglomeration for performing RDE tests. The creation of a test route in line with the requirements of the latest 
emission standards is currently one of the most difficult aspects of this type of research. For this reason, it was assumed that the route will be referred to as the PoznańRDE test route and on it the authors will perform RDE tests in accordance with the applicable procedures for PC and LDV category vehicles. For the tested vehicle, the degree of hybridization during the whole test was $46 \%$ and its highest value occurred in the urban and rural sections. In the motorway section, the electric motor propulsion of the hybrid drive system was not used. The high share of electric motor use in the urban section ended up limiting the conversion rate of the TWC catalytic converter, which in turn resulted in a very large value of $\mathrm{NO}_{\mathrm{x}}$ emission in this test section - it was higher than for the motorway section. The CF coefficients for $\mathrm{CO}$ and $\mathrm{NO}_{\mathrm{x}}$ determined both from the entire RDE test and the EMROAD method were larger than currently defined by the emission norms. For this reason, it is necessary to perform further RDE measurements for motor vehicles in the PC and LDV category in order to check the correctness of the definition of the $\mathrm{CF}$ factor by the legislator.

\section{References}

1. K. Andrzejczak, J. Selech, Transport Problems 12, 103-111 (2017), DOI: 10.20858/tp.2017.12.3.10.

2. J. Merkisz, M. Andrzejewski, A. MerkiszGuranowska, I. Jacyna-Gołda, Journal of KONES Powertrain and Transport 21, 219-226 (2014)

3. J. Merkisz, M. Idzior, J. Pielecha, W. Gis, WIT Transactions on the Built Environment 111, 181-189 (2010), DOI: 10.2495/UT100171

4. J. Merkisz, P. Lijewski, P. Fuc, S. Weymann, Eksploatacja i Niezawodnosc - Maintenance and Reliability 15, 364-368 (2013)

5. J. Zak, R. Jachimowski, P. Golebiowski, Transport Means - Proceedings of the International Conference, 772-777 (2016)

6. J. Merkisz, J. Pielecha, IOP Conference SeriesMaterials Science and Engineering 148, UNSP $012078 \quad$ (2016), DOI: $\quad 10.1088 / 1757$ $899 X / 148 / 1 / 012078$
7. J. Pielecha, J. Merkisz, J. Markowski, R. Jasinski, E3S Web of Conferences 10, UNSP 00073 (2016), DOI: $10.1051 / \mathrm{e} 3$ sconf $/ 20161000073$

8. J. Merkisz, J. Pielecha, W. Gis, Proceedings of the Ninth Asia-Pacific International Symposium on Combustion and Energy Utilization, 477-482 (2008)

9. J. Merkisz, M. Bajerlein, P. Daszkiewicz, Lecture Notes in Information Technology 13, 106-113 (2012)

10. J. Merkisz, P. Lijewski, P. Fuc, S. Weymann, Applied Engineering in Agriculture 31, 875-879 (2015), DOI: 10.13031/aea.31.11225

11. B. Kurc, Journal of Solid state electrochemistry $\mathbf{1 8}$, 2035-2046 (2014), DOI: 10.1007/s10008-014-2451-x

12. D. Dolinski, E. Odachowska, Accident Analusis and Prevention 115, 73-78 (2018), DOI: 10.1016/j.aap.2018.03.007

13. Commission Regulation (EC) 692/2008 of 18 July 2008 implementing and amending Regulation (EC) No 715/2007 of the European Parliament and of the Council on type-approval of motor vehicles with respect to emissions from light passenger and commercial vehicles (Euro 5 and Euro 6) and on access to vehicle repair and maintenance information, 2008

14. Commission Regulation (EC) $715 / 2007$ of the European Parliament and of the Council of 20 June 2007 on type approval of motor vehicles with respect to emissions from light passenger and commercial vehicles (Euro 5 and Euro 6) and on access to vehicle repair and maintenance information, 2007

15. http://gpsvisualizer.com (access: 24.06. 2019)

The research was funded by European Union from European Regional Development Fund through the National Centre for Research and Development (Narodowe Centrum Badań i Rozwoju) - research project within the Smart Growth Programme (contract No. POIR.04.01.02-00-0002/18).

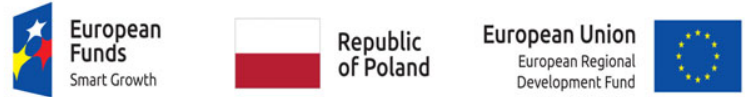

